\title{
Diffusive Phenomena and the Austenite/Martensite Relative Stability in Cu-Based Shape-Memory Alloys
}

\author{
J. L. Pelegrina ${ }^{1,2,3} \cdot$ A. Yawny ${ }^{1,2,3} \cdot$ M. Sade ${ }^{1,2,3}$
}

Published online: 26 February 2018

(C) ASM International 2018

\begin{abstract}
The main characteristic of martensitic phase transitions is the coordinate movement of the atoms which takes place athermally, without the contribution of diffusion during its occurrence. However, the impacts of diffusive phenomena on the relative stability between the phases involved and, consequently, on the associated transformation temperatures and functional properties can be significant. This is particularly evident in the case of $\mathrm{Cu}$ based shape-memory alloys where atomic diffusion in both austenite and martensite metastable phases might occur even at room-temperature levels, giving rise to a variety of intensively studied phenomena. In the present study, the progresses made in the understanding of three selected diffusion-related effects of importance in $\mathrm{Cu}-\mathrm{Zn}-\mathrm{Al}$ and $\mathrm{Cu}-\mathrm{Al}-\mathrm{Be}$ alloys are reviewed. They are the after-quench retained disorder in the austenitic structure and its subsequent reordering, the stabilization of the martensite, and the effect of applied stress on the austenitic order. It is shown how the experimental results obtained from tests performed on single crystal material can be rationalized under the shed of a model developed to evaluate the variation of the relative stability between the phases in terms of atom pairs interchanges.
\end{abstract}

Keywords Equilibrium temperature $\cdot$ Martensite

Austenite $\cdot \mathrm{Cu}-\mathrm{Zn}-\mathrm{Al} \cdot \mathrm{Cu}-\mathrm{Al}-\mathrm{Be}$

$\triangle$ J. L. Pelegrina

jlp201@cab.cnea.gov.ar

1 Centro Atómico Bariloche, CNEA, Av. E. Bustillo 9500, R8402AGP, San Carlos de Bariloche, Argentina

2 Instituto Balseiro, CNEA and Universidad Nacional de Cuyo, Bariloche, Argentina

3 CONICET, Buenos Aires, Argentina

\section{Introduction}

In the present study, the research performed on the effects of the diffusion of point defects and its consequences on the relative stability between the austenite (referred to as $\beta$ phase in what follows) and martensitic phases (18R, $2 \mathrm{H}$, 6R) in Cu-based shape-memory alloys (SMA) is briefly reviewed. This has been object of intensive study to which Prof. Jan Van Humbeeck has contributed significantly along his fruitful scientific career. Proof of his extensive contribution is that his vast list of publications begins in 1977 first with a study on $\mathrm{Cu}-\mathrm{Zn}-\mathrm{Al}$ alloys [1], which was motivated by the possibility of reducing severe vibrations and noise in mechanical devices using the high damping capacity that these alloys exhibit in the martensitic state. Damping properties were evaluated using internal friction techniques, and an important aspect of the study was the consideration of using specimens that were produced as single crystals in the austenitic state. In that way, the contributions to the internal friction signal of the martensite from the former austenite grain boundaries were completely eliminated. One of the main findings of that article was that aging of the martensite resulted in a strong increment of the $A_{S}$ temperature, i.e., the temperature for the start of its reverse transformation to austenite. This effect was referred to as the stabilization of martensite, and its occurrence was one of the main drawbacks for introducing $\mathrm{Cu}$-based SMAs in real applications. At that time, as it has already been shown that point defects in $\beta$-brass were highly mobile, even at room temperature [2], stabilization was proposed to occur by the migration of mobile defects to martensitic interfaces where they should exert a strong pinning action.

Next in the publications list of Prof. Jan Van Humbeeck, we find a study of pseudoelasticity in $\mathrm{Cu}-\mathrm{Zn}-\mathrm{Al}$ alloys, 
both in mono- and in polycrystalline materials [3]. Linear dependency between the critical stress to induce the martensite and the temperature was reported. It was also found that the elastic modulus of the austenite has a positive temperature coefficient, thus indicating that a progressive softening of its lattice is occurring as the transformation temperature is approached.

In the International Conference on Martensitic Transformations (ICOMAT) that took place in Leuven (Belgium) in August 1982, Prof. Jan Van Humbeeck presented a new paper on the stabilization of $\mathrm{Cu}-\mathrm{Zn}-\mathrm{Al}$ alloys [4]. In that study, the influences of aging treatments in $\beta$-phase and in martensite on the relative stability between the phases were experimentally characterized. At that time, a controversy between two models attempting to rationalize the stabilization of the martensite had aroused. The first was the already introduced mechanisms of pinning of martensite interfaces. It found support on internal friction experiments like those described in [5]. Structural order evolution due to atomic rearrangements was proposed as a feasible alternative by Rapacioli and Ahlers [6], who studied the influence of short-range disorder on the martensitic transformation in $\mathrm{Cu}-\mathrm{Zn}$ and $\mathrm{Cu}-\mathrm{Zn}-\mathrm{Al}$ alloys. At that time, more arguments favored the former explanation, because it was believed that order of the $\beta$-phase was of the $\mathrm{DO}_{3}$ type [7], instead of the $\mathrm{L}_{1}$ type as accepted nowadays.

The following research on stabilization of martensite carried out by Prof. Van Humbeeck and coworkers was published as a four-paper series in Scripta Metallurgica [8-11]. In the first study [8], a systematic experimental study on the influences of the aging temperature and holding time on the magnitude of the stabilization, determined by the increment in the $A_{S}$ temperature, was performed. The authors concluded that the stabilization of martensite is a complex process driven by the diffusion of an excess number of vacancies retained by quenching in a partially ordered lattice, order of which is in turn evolving. As mentioned before, the excess vacancies may diffuse to different defects and may pin the martensite plate boundaries, making the reverse transformation more difficult. In the second paper, analysis by X-ray diffraction proved that atomic rearrangements also occurred in martensite during stabilization, resulting in a modification of the martensite lattice parameters [9]. The resulting crystallographic relation between the $\beta$-phase and martensite was shown to not correspond to an invariant plane condition, and this was considered as an additional possible cause for the observed increase in $A_{S}$. However, using the phenomenological theory of martensitic transformations, Lovey and Pelegrina [12] showed that with the change in martensite lattice parameters, the invariant plane condition could still be achieved by considering habit planes which are only barely rotated (few degrees) with respect to the initial one. In that way, no hindering of the reverse motion of the interphases might occur, i.e., the reverse transformation would take place without any increase in $A_{S}$, or equivalently, it would proceed without a higher thermal hysteresis. In the third paper of the series [10], the vacancy kinetics was analyzed using the positron annihilation technique. It was observed that vacancy annihilation took place in the $\beta$-phase, while no measurable annealing out of vacancies occurred in the martensite. This study also proved that there exists a correlation between the heat treatment, the vacancy concentration, and the kinetics of stabilization process. The aim of the fourth paper was to characterize the microstructure of the stabilized martensite using transmission electron microscopy [11]. Extra contrast detected at the martensite plates boundaries, at type I and II defects and inside the bulk martensite, was considered evidence of the occurrence of pre-precipitation processes and vacancy clustering in the stabilized martensite. These latter findings were interpreted as responsible of the pinning mechanism. At the same time, Scarsbrook et al. [13] were proving additional experimental evidence supporting pinning and/or atom rearrangements as the responsible mechanisms behind martensite stabilization, ruling out the possible changes in the faulted structure of the martensite as the origin of the effect.

After the aforementioned seminal studies, an important effort was made in several groups pursuing a more clear understanding of the acting mechanisms for a wider range of Cu-based alloys. In line with this aim, Prof. Van Humbeeck's team has studied several families of alloys, including $\mathrm{Cu}-\mathrm{Zn}-\mathrm{Al}$ [14-22], $\mathrm{Cu}-\mathrm{Al}-\mathrm{Ni}$ [23-30], $\mathrm{Cu}-\mathrm{Al}-$ $\mathrm{Be}$ [31-36], $\mathrm{Cu}-\mathrm{Al}[37,38]$, and a comparison of results was presented in $[39,40]$. Of particular relevance was the finding of the phenomena referred to by these authors as the hyperstabilization of martensites. This was demonstrated in $\mathrm{Cu}-\mathrm{Al}-\mathrm{Be}$ and $\mathrm{Cu}-\mathrm{Zn}-\mathrm{Al}$ alloys [34-36] where up to $300 \mathrm{~K}$ upward shifts of the $\mathrm{A}_{\mathrm{S}}$ temperatures were detected. The occurrence of a similar phenomenon had been at that time already reported in the case of the $18 \mathrm{R}$ martensite phase in $\mathrm{Cu}-\mathrm{Zn}-\mathrm{Al}$ [13]. Its occurrence in the $2 \mathrm{H}$ martensite in the same system was reported later in [41].

The previous results highlight the particular sensitivity of Cu-based alloys to martensite stabilization effects. This is the most important atomic diffusion-related process in this SMA family of alloys, but not the single one which might alter the relative stability between the phases involved. The aim of the present study is to contribute to the understanding of these diffusion-related effects in $\mathrm{Cu}$ based SMA by presenting a unified approach based on the effects of atomic pair interchanges. In particular, $\mathrm{Cu}-\mathrm{Zn}-$ $\mathrm{Al}$ and $\mathrm{Cu}-\mathrm{Al}-\mathrm{Be}$ alloys will be considered. Three phenomena will be analyzed here using a model developed to 
calculate the free energy variations that are produced in the austenite and martensite by specific atom interchanges and that can be used to evaluate the variation of the relative stability between the phases. They are the impact of quenching the austenite and its recovery, the stabilization of martensite, and the effect of aging the $\beta$-phase under load. Experimental results obtained in monocrystalline samples will be mainly considered. In what follows, $M_{S}$ and $\mathrm{M}_{\mathrm{F}}\left(\mathrm{A}_{\mathrm{S}}\right.$ and $\left.\mathrm{A}_{\mathrm{F}}\right)$ are used to denote the start and end temperatures of the forward (reverse) transformation from austenite to martensite (martensite to austenite), respectively.

\section{Atomic Order in the Austenite of Cu-Based Shape- Memory Alloys}

The long-range order in Cu-based alloys can be adequately described by subdividing the high temperature bcc lattice of the $\beta$-phase into four interpenetrating fcc sublattices [42]. Figure 1 shows eight ( $\left.\begin{array}{lll}2 & 2 & 2\end{array}\right)$ body centered cubic (bcc) cells, accommodated in a cube of edge twice as long as the bcc parameter. In this bigger cube, the four interpenetrating face-centered cubic (fcc) cells can be defined as shown in Fig. 1a. They will be denoted as sublattices $(i=1-4)$. It has to be mentioned here that some authors use a slightly different nomenclature, associating sublattices 1 and 2 with a single sublattice referred to as $\alpha$, and assigning the names $\beta$ and $\gamma$ to sublattices 3 and 4 , respectively [43]. No vacancies are taken into account in this description, and therefore, in each position, an atom has to be placed. As the alloys are non-stoichiometric, instead of associating an atom with each position, it is more convenient to assign an occupation probability $P_{\mathrm{A}}^{(\mathrm{i})}$ of finding an atom $A$ in each sublattice $i$. The way to define the occupation probabilities can be found elsewhere [42].

In what follows, an example of type and degree of ordering in terms of different occupation probabilities is given for the ideal case of $\mathrm{Cu}-\mathrm{Zn}-\mathrm{Al}$ alloys. $C_{\mathrm{A}}$ is the concentration expressed as the atomic fraction of element $\mathrm{A}$, with the restriction $C_{\mathrm{Zn}}$ and $C_{\mathrm{Al}}$ to be both below 0.25 .

When the austenite is at high temperature, no distinction can be made between the four sublattices because the atoms of the different elements distribute over the entire cell with a probability given by their respective concentrations. This corresponds to the well-known A2 lattice or simply bcc (Fig. 1b) and represents a situation of disorder described by

$$
\begin{aligned}
& P_{\mathrm{Cu}}^{(1)}=P_{\mathrm{Cu}}^{(2)}=P_{\mathrm{Cu}}^{(3)}=P_{\mathrm{Cu}}^{(4)}=C_{\mathrm{Cu}} \\
& P_{\mathrm{Zn}}^{(1)}=P_{\mathrm{Zn}}^{(2)}=P_{\mathrm{Zn}}^{(3)}=P_{\mathrm{Zn}}^{(4)}=C_{\mathrm{Zn}} \\
& P_{\mathrm{Al}}^{(1)}=P_{\mathrm{Al}}^{(2)}=P_{\mathrm{Al}}^{(3)}=P_{\mathrm{Al}}^{(4)}=C_{\mathrm{Al}}
\end{aligned}
$$

On lowering the temperature, the austenite becomes ordered. The type and degree of ordering depends on several parameters as, for example, the particular elements of the alloy, the composition, the ordering temperatures, the thermal treatment, etc. When it is possible to define two different sets of occupation probabilities, two types of ordered structures might be obtained. One of them occurs when one of the probabilities set is assigned to sublattices 1 and 2 , and the other to sublattices 3 and 4 . In this case, B2 order manifests (Fig. 1c). For the aforementioned $\mathrm{Cu}-\mathrm{Zn}-$ $\mathrm{Al}$ alloy, this is expressed by

$$
\begin{array}{ll}
P_{\mathrm{Cu}}^{(1)}=P_{\mathrm{Cu}}^{(2)}=1 & P_{\mathrm{Cu}}^{(3)}=P_{\mathrm{Cu}}^{(4)}=C_{\mathrm{Cu}}-C_{\mathrm{Zn}}-C_{\mathrm{Al}} \\
P_{\mathrm{Zn}}^{(1)}=P_{\mathrm{Zn}}^{(2)}=0 & P_{\mathrm{Zn}}^{(3)}=P_{\mathrm{Zn}}^{(4)}=2 C_{\mathrm{Zn}} \\
P_{\mathrm{Al}}^{(1)}=P_{\mathrm{Al}}^{(2)}=0 & P_{\mathrm{Al}}^{(3)}=P_{\mathrm{Al}}^{(4)}=2 C_{\mathrm{Al}}
\end{array}
$$

The other alternative appears when the same occupation probabilities set holds for sublattices 1,2 , and 3, it being different only for sublattice 4 (Fig. 1d). This corresponds to $\mathrm{DO}_{3}$ order, and the following probabilities result:

$$
\begin{aligned}
& P_{\mathrm{Cu}}^{(1)}=P_{\mathrm{Cu}}^{(2)}=P_{\mathrm{Cu}}^{(3)}=\frac{4 C_{\mathrm{Cu}}}{3} \quad P_{\mathrm{Cu}}^{(4)}=0 \\
& P_{\mathrm{Zn}}^{(1)}=P_{\mathrm{Zn}}^{(2)}=P_{\mathrm{Zn}}^{(3)}=1-\frac{4 C_{\mathrm{Cu}}}{3} \quad P_{\mathrm{Zn}}^{(4)}=1-4 C_{\mathrm{Al}} \\
& P_{\mathrm{Al}}^{(1)}=P_{\mathrm{Al}}^{(2)}=P_{\mathrm{Al}}^{(3)}=0 \quad P_{\mathrm{Al}}^{(4)}=4 C_{\mathrm{Al}}
\end{aligned}
$$

For the description of the remaining ordered structure, denoted as L2 1 (Fig. 1e), it is necessary to define three different sets of occupation probabilities. One of them is assigned to sublattices 1 and 2 , and the remaining two to each of sublattices 3 and 4 . For the $\mathrm{Cu}-\mathrm{Zn}-\mathrm{Al}$ example being considered, the occupation probabilities are given by

$$
\begin{array}{ccc}
P_{\mathrm{Cu}}^{(1)}=P_{\mathrm{Cu}}^{(2)}=1 & P_{\mathrm{Cu}}^{(3)}=4 C_{\mathrm{Cu}}-2 & P_{\mathrm{Cu}}^{(4)}=0 \\
P_{\mathrm{Zn}}^{(1)}=P_{\mathrm{Zn}}^{(2)}=0 & P_{\mathrm{Zn}}^{(3)}=3-4 C_{\mathrm{Cu}} & P_{\mathrm{Zn}}^{(4)}=1-4 C_{\mathrm{Al}} \\
P_{\mathrm{Al}}^{(1)}=P_{\mathrm{Al}}^{(2)}=0 & P_{\mathrm{Al}}^{(3)}=0 & P_{\mathrm{Al}}^{(4)}=4 C_{\mathrm{Al}}
\end{array}
$$

The use of different symbols in Fig. 1 to denote the atomic positions reflects the possibility of having different occupation probabilities in each of the order configurations, as was exemplified by Eqs. (1) through (4). The kind of ordering reactions and the temperature of occurrence for each alloy can be found in the literature, see for example [42].

\section{Feasibility of Perfect Order in Austenite}

Martensitic transformation temperatures in Cu-based alloys are strongly dependent on composition and also on other factors like microstructure and atomic order [44, 45]. In fact, the effects of these contributions are difficult to discriminate since, for example, usual thermal treatments 

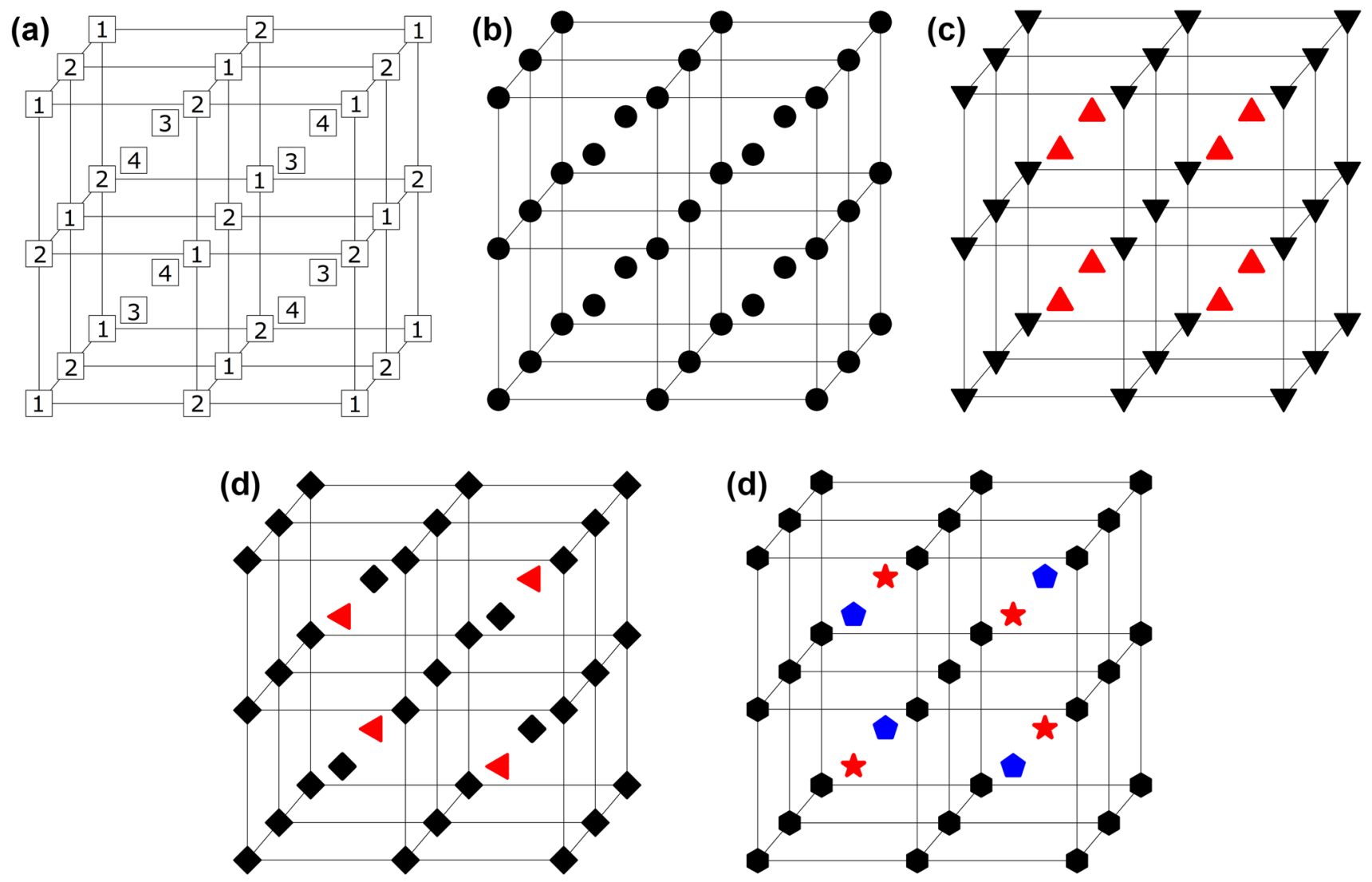

Fig. 1 Cube formed by eight bcc cells used to define the different atom distributions in Cu-based alloys. a Definition of the four interpenetrating fcc sublattices. b A2-disordered lattice. c, d, and e the ordered structures $\mathrm{B} 2, \mathrm{DO}_{3}$, and $\mathrm{L} 2{ }_{1}$, respectively

might affect simultaneously both the microstructure and the degree of order, and in some particular cases also the composition. As a rule of thumb, the higher the temperature at which order becomes favorable, the higher the degree of order that can be present at temperatures close to the martensitic transformation temperatures. In this sense, an interesting example reported several years ago by Rapacioli and Ahlers [6] on the effect of quenching on $\mathrm{M}_{\mathrm{S}}$ is worth to be recalled. These authors used electrical resistivity measurements to determine $\mathrm{M}_{\mathrm{S}}$ after quenching the austenite from different quench temperatures $T_{\mathrm{Q}}$ to a temperature above $\mathrm{M}_{\mathrm{S}}$. Time aging intervals at $T_{\mathrm{Q}}$ were sufficiently short to avoid decomposition of the austenite. Variations of $\mathrm{M}_{\mathrm{S}}$ up to $40 \mathrm{~K}$ were observed for $T_{\mathrm{Q}}$ temperatures in the range from $373 \mathrm{~K}$ up to $933 \mathrm{~K}$.

A detailed analysis of these results was performed for specimens quenched from temperatures below $473 \mathrm{~K}$. The authors could explain the reported $\mathrm{M}_{\mathrm{S}}$ variations (decrease) by a quenched-in disorder retained in the long-rangeordered matrix. The disorder was associated with wrong $\mathrm{Cu}-\mathrm{Zn}$ pairs generated by the interchange of next-nearestneighbor atoms from sublattices 3 and 4, respectively, having a low energy of formation in the austenite. The existence of the aforementioned disordered pairs of atoms explains the observed changes in $\mathrm{M}_{\mathrm{S}}$ because they produce a variation of the internal energy, resulting in an increase of the energy of the martensite relative to the $\beta$-phase. A larger energy of martensite makes its formation more difficult, leading to the observed decrease in $\mathrm{M}_{\mathrm{S}}$.

Additional variations in $M_{S}$ were detected after annealing the quenched specimens in austenite at $273 \mathrm{~K}$ [6]. These results clearly indicated that, at temperatures as low as $273 \mathrm{~K}$, atomic diffusion in the austenite takes place, enabling the evolution toward long-range order. It is worthy to mention here that as this process increases the $M_{S}$ obtained after the quench, a very interesting phenomenon can happen for an alloy with a nominal $\mathrm{M}_{\mathrm{S}}$ temperature slightly above the testing temperature $\left(T_{\mathrm{T}}\right)$. In this case, aging will make $\mathrm{M}_{\mathrm{S}}$ to evolve from below $T_{\mathrm{T}}$ (the quenched condition) to above $T_{\mathrm{T}}$ (the recovered condition). Therefore, at one point, $\mathrm{M}_{\mathrm{S}}$ will exceed $T_{\mathrm{T}}$ and the material will appear as transforming in an isothermal way. This must be rationalized as the combined effect of the martensitic transformation (athermal in character) and the evolution of the austenite by an atomic ordering process taking place to reduce its free energy, altered by a previous quench. 
Following the analogous procedures as mentioned before, Planes et al. [46] determined variations of martensitic transformation temperatures after quenching from different temperatures $T_{\mathrm{Q}}$ using calorimetric measurements. In that study, similar variations of the temperatures $\mathrm{M}_{\mathrm{S}}, \mathrm{M}_{\mathrm{F}}, \mathrm{A}_{\mathrm{S}}$, and $\mathrm{A}_{\mathrm{F}}$ as those reported by Rapacioli and Ahlers [6] were reported. In addition, the same qualitative dependence of the heat exchanged during the transformation with the temperature $T_{\mathrm{Q}}$ was obtained. This latter result is expected due to the independency on $T_{\mathrm{Q}}$ of the entropy change associated with the austenite-to-martensite transition. Planes et al. [46] measured the acoustic emission simultaneously with the heat exchanged during transformation. Their results showed that acoustic emission is strongly affected by the actual vacancy concentration of the material but not by the state of order in the austenite.

As stated above, changes in $\mathrm{M}_{\mathrm{S}}$ after quenching from high temperatures and/or on further aging at temperatures close to room temperature can be associated with retained disorder or reordering. Additional confirmation of this fact was obtained by measuring the variation of the critical stresses necessary to induce the transformation after similar thermal heat treatments [47]. In that reference, Planes et al. have shown that, using $\mathrm{Cu}-\mathrm{Zn}-\mathrm{Al}$ single crystals of an appropriate composition, it is possible to avoid the L2 order by a quench from a temperature $T_{\mathrm{Q}}$ slightly above the selected low L2 1 ordering temperatures. In the temperature range where only B2 order develops, a constant value of the critical transformation stress was observed. A second interesting fact derived from the study comes from the analysis of the reported changes in the critical stress to obtain the 18R martensite after quenching and aging [47]. They concluded that in order to obtain the highest possible degree of $\mathrm{L} 2{ }_{1}$ order, it is more appropriate to do a suitable combination of a quench from around $650 \mathrm{~K}$ and room-temperature aging than to simply air cool the material from high temperatures. This is because quenching from temperatures $T_{\mathrm{Q}}$ around $650 \mathrm{~K}$ allows maximizing the amount of vacancies that can be retained. This has been further corroborated using positron lifetime spectroscopy in [48-50]. In fact, the kinetics of the reordering process of the $\beta$-phase depends on the temperature that is reached during the previous heat treatment because this leads to different amount of retained vacancies. It also depends on the degree of order because only specific jump sequences of the vacancies are allowed in these partially ordered structures.

It is very important to remark here that the experimental results of the effect of changes in $\mathrm{L} 2{ }_{1}$ order on $\mathrm{M}_{\mathrm{S}}$ have been obtained using different experimental techniques, i.e., those detecting changes associated with thermally induced transformation (determination of transformation temperatures using electrical resistivity and calorimetry) and those detecting changes associated with stress-induced transformations (determination of critical stresses in mechanical tests). The Clausius-Clapeyron relationship enables to correlate temperature variations with stress variations obtained from temperature- and stress-driven transformations, respectively. The very good correlation observed can be considered a good indicator that the measured evolutions are related to changes in the relative thermodynamic stability between the phases involved. However, it should also be mentioned here that the precise magnitude of the changes are influenced by factors like the time interval elapsed between the quench and the measurement, as well as by the absolute dimensions of the specimen due it its relation with the effective distance to vacancy sinks. This was clearly shown by Sesma et al. [51] who analyzed data obtained from different experimental techniques. The same authors reported that repeated thermal treatments might also lead to the evaporation of $\mathrm{Zn}$, which contribute to small changes of the transformations temperatures. These effects should be taken into account when the precise magnitude of the contribution of the retained short-range disorder wants to be assessed.

Results presented so far for monocrystalline $\mathrm{Cu}-\mathrm{Zn}-\mathrm{Al}$ SMA enabled to corroborate that disorder and an excess concentration of vacancies are retained after quenching from different temperatures. Both the degree of disorder and the excess content of vacancies decrease during aging. In their succession of jumps along their paths to the different annihilation sinks, vacancies contribute positively by enhancing the ordering kinetics. The transformation temperatures in $\mathrm{Cu}-\mathrm{Zn}-\mathrm{Al}$ alloys are not affected by the absolute vacancy content of the material, it being solely determined by the degree of order. The possible influence of other type of defects, or even due to the occurrence of precipitation processes, which actually takes place after step quenching from high temperatures [52], can be here completely disregarded.

A rather different overall situation is found in $\mathrm{Cu}-\mathrm{Al}-\mathrm{Be}$ alloys. Here, on the one hand, thermal treatments performed at high $T_{\mathrm{Q}}$ levels also affect the critical transformation temperatures. Several papers have reported the effect of thermal treatments performed in austenite phase on the martensitic transformation temperatures. These studies had been conducted with the purpose of understanding the effect and also with the intention of identifying suitable thermal treatments to optimize functional properties [53-55]. In the case of the $\mathrm{Cu}-\mathrm{Al}-\mathrm{Be}$ alloys, it has been reported that the austenitic structure shows only one phase transition leading to long-range order. This has been described either as $\mathrm{DO}_{3}$ or $\mathrm{L}_{1}[42,43,54,56]$.

Thermal treatments which include aging at high $T_{\mathrm{Q}}$ temperatures followed by quenching down to temperatures close to room temperature, but above $\mathrm{M}_{\mathrm{S}}$, lead to an 
increase in $\mathrm{M}_{\mathrm{S}}$ as $T_{\mathrm{Q}}$ is increased [56]. Further aging at room temperature results in a slight decrease of the $M_{S}$ temperatures. The same authors explained the variations in $\mathrm{M}_{\mathrm{S}}$ as due to a retained $\mathrm{L} 2{ }_{1}$ disorder during the quench and due to further reordering during subsequent aging at room temperature. For that purpose, they used a model which accounts for the $\mathrm{M}_{\mathrm{S}}$ variations by considering the atom pairs interaction energies, mainly those corresponding to the $\mathrm{Cu}-\mathrm{Al}$ nearest-neighbor pairs in martensite and up to the $\mathrm{Cu}-\mathrm{Al}$ next-nearest-neighbor pairs in austenite [57]. The variations of $\mathrm{M}_{\mathrm{S}}$ were explained in a similar way as in the case of the aforementioned $\mathrm{Cu}-\mathrm{Zn}-\mathrm{Al}$ single crystals. However, Mañosa et al. have shown that aging performed at room temperature after quenching from high temperatures induced similar functional time evolutions in $\mathrm{M}_{\mathrm{S}}$ and in vacancy concentration, as determined by using positron annihilation technique [58, 59]. Additionally, no further changes in the degree of order were observed using neutron scattering [59-61]. These results led the authors to suggest that the concentration of Be, which is altered by the concentration of vacancies, might explain the shifts observed in $\mathrm{M}_{\mathrm{S}}$ after the thermal treatments performed in austenite.

It is interesting to mention that shifts in martensitic transformation temperatures might also arise from small changes in Be concentration as it has been reported by Lopez-Ferreño et al. [54]. As was mentioned before for the case of $\mathrm{Cu}-\mathrm{Zn}-\mathrm{Al}$, these composition-related effects have to be taken into account when precise evaluations of the different contributions are required.

\section{Stabilization of Martensite (or How Martensite Dislikes the Atom Configuration Inherited from Austenite)}

Stabilization of the martensite in $\mathrm{Cu}$-based alloys has been object of intensive study in the last four decades. It is possible to find in the literature studies of aging experiments that has been carried out under a wide variety of alloys and experimental conditions. A certain incomplete list would include: binary, ternary and quaternary alloys; different concentration of the constituting elements; monoand/or polycrystalline specimens; varying densities of different defects, including vacancies and dislocations; specimens with different shapes and sizes; temperature- and/or stress-induced transformations (i.e., polyvariant vs. single variant martensite, respectively); different aging temperatures and stress levels; and different heat treatments prior to aging, etc. Providing a comprehensive list of references clearly exceeds the scope of the present brief review, but the interested reader could take advantage of Prof. Jan Van Humbeeck's publication list and references included therein.
In all cases, the reverse transformation to austenite has been found to shift in such a way that the martensitic phase extends its temperature and stress ranges of stability. Most of the experiments performed to obtain experimental data on stabilization of martensite consist in comparing the transformation temperatures/stresses before and after subjecting the specimens to different thermomechanical treatments. Usually strong differences in the magnitude of stabilization, expressed in temperature or equivalent resolved shear stress units, can be found depending on the phase reached during the thermal treatment. For the same $T_{\mathrm{Q}}$ temperature, it is larger when the sample is quenched down directly into the martensite field. It was mentioned before that cooling from high temperature leaves some degree of disorder in the $\mathrm{L} 2{ }_{1}$-ordered $\mathrm{Cu}-\mathrm{Zn}-\mathrm{Al}$ austenite and an excess of vacancies with respect to what would be the equilibrium concentration at the low temperature. A thorough study on the effects of the quenching temperature $T_{\mathrm{Q}}$ and subsequent aging time in $18 \mathrm{R}$ martensite on the relative phase stability was performed by Abu Arab and Ahlers [62] using $\mathrm{Cu}-\mathrm{Zn}-\mathrm{Al}$ monocrystalline specimens. Those authors measured the decrease of the critical resolved retransformation shear stress $(\Delta \tau)$ of partially transformed tensile-stressed samples at selected temperatures, after quenching from different temperatures $T_{\mathrm{Q}}$ between 573 and $773 \mathrm{~K}$. The values of $\Delta \tau$ were then converted through the Clausius-Clapeyron relationship to a corresponding variation $\Delta \mathrm{A}_{\mathrm{F}}$ (temperature increase) of the austenite finish transformation temperature. Due to their forcefulness, the obtained results are summarized as follows:

(a) The intensity of the martensite stabilization effects expressed in terms of $\Delta \tau$ (equivalently, $\Delta \mathrm{A}_{\mathrm{F}}$ ) increases with the aging time elapsed in martensite;

(b) $\Delta \tau$ increases with the aging temperature in martensite;

(c) Faster kinetics is obtained when a higher vacancy concentration is retained after quenching;

(d) Stabilization intensity tends to a saturation value which, as an example, can result in $\Delta \tau$ close to $120 \mathrm{MPa}$ (equivalently, $\Delta \mathrm{A}_{\mathrm{F}} 120 \mathrm{~K}$ ) after aging at $315 \mathrm{~K}$.

e) The saturation value of $\Delta \tau$ increases with the aging temperature, although sometimes, it cannot be measured with sufficient precision as the sample decomposes during heating at the higher aging temperatures.

(f) The saturation value of $\Delta \tau$ decreases when the material is previously aged in austenite for a certain time before aging it in martensite. This can be explained by the annealing out of vacancies that takes place in the $\beta$-phase. This is a substantial 
aspect that has been since then used to design optimal step quenching heat treatments with the intention of reducing the stabilization proneness. Further details can be found in the original paper [62].

It should be also noticed that stabilization magnitudes considerably larger than those reported in [62] for $18 \mathrm{R}$ martensite can be found in $\mathrm{Cu}-\mathrm{Zn}-\mathrm{Al}$ alloys. In this alloy, $2 \mathrm{H}$ martensitic monocrystalline specimens can be stress induced, and, if these $2 \mathrm{H}$ crystals are further stressed [63], a second-order phase transition takes place at a critical stress referred to by the authors as $\sigma_{T 1}$. A remarkable difference in stabilization intensity was reported for aging experiments performed at stresses below or above $\sigma_{T 1}$. In the former case, weak stabilization effects were found, similar to the ones reported for the $18 \mathrm{R}$ structure in [64]. If instead aging is performed at stresses above $\sigma_{T 1}$, up to $315 \mathrm{~K}$ of stabilization with a faster kinetics was observed. These results had been rationalized by the authors considering changes in order, in lattice parameters and also considering the accompanying elastic distortions.

One remarkable aspect common to the previously described experiments is that aging at temperatures as low as room temperature is enough to get significant kinetics associated to the stabilization of martensite. This is one of the main aspects to be solved if $\mathrm{Cu}-\mathrm{Zn}-\mathrm{Al}$ alloys are to be used in technological devices. It is clear that this effect is enhanced when vacancies in excess are retained but this, on the other hand, is the usual condition after performing the standard thermal treatments. It is also important to mention here that the previously described experiments were designed to enhance the effects of stabilization, precisely because this was the object of study. Thus, the stabilization tests were performed under conditions where the concentration of vacancies was considerably higher than the equilibrium values. From the point of view of the applications, it is convenient that stabilization effects are minimized. In this sense, only few experiments have been reported in the literature where stabilization was analyzed under conditions which can be considered much closer to equilibrium with respect to vacancy concentration (e.g., Yawny et al. [65]). In that study, authors analyzed the effects of diffusional processes on the pseudoelastic fatigue of $\mathrm{Cu}-\mathrm{Zn}-\mathrm{Al}$ monocrystals. As part of the study, they performed stabilization tests after having obtained a precisely defined reference state. In order to get it, tensile specimens were first heat treated by air cooling from 1123 to $333 \mathrm{~K}$, which is above the $\mathrm{M}_{\mathrm{S}}$ temperature of the material. This temperature was then kept constant during the rest of the test. Firstly, the evolution of the stress-strain response was followed by performing periodic single pseudoelastic cycles. After approximately 2 days, an asymptotic stress-strain curve behavior was detected, i.e., no discernible changes between successive interspersed pseudoelastic cycles could be detected. This condition was considered to define the reference state. It was assumed that the equilibrium concentration of vacancies for the $333 \mathrm{~K}$ temperature was reached. Stabilization tests were then performed following the same procedure used in [62]. Stabilization of $4 \mathrm{~K}$ maximum magnitude was observed. The effect reverted completely after keeping the specimen enough time in the $\beta$-phase after unloading and the reference state was recovered. It was clear from these experiments that extra vacancies are not required for the stabilization of martensite to manifest. Moreover, the evolution of the functional properties detected during pseudoelastic cycling the $\mathrm{Cu}-\mathrm{Zn}-\mathrm{Al}$ monocrystals after reaching the reference state could be explained in terms of the superposition of two phenomena: the stabilization of martensite and the posterior recovery of the austenite phase. This recovery refers to the phenomenon that takes place in the $\beta$-phase after the reverse transformation of the stabilized martensite. It is evident that the inherited order of the $\beta$-phase in this condition will differ from the one it had in the state previous to the transformation to martensite.

Although the analysis of stabilization under dynamic conditions is out of the scope of the present paper, an additional important result reported in [65] is worthy to be mentioned. Additional tests performed on the specimens in their recovered state after cycling have shown that the martensite does not further stabilize, at least using similar time intervals as those considered in the experiments described in the previous paragraph. These results suggest that the kinetics of diffusive phenomena are affected by the microstructure. Defects introduced during cycling, in the present case dislocations and/or dislocation arrays, act as efficient sinks for vacancies, thus causing a retardation in the kinetics of both the stabilization and the posterior recovery of the austenite [65].

Martensite stabilization in $\mathrm{Cu}-\mathrm{Al}-\mathrm{Be}$ alloys has also been characterized using a concentration of vacancies greater than the corresponding one to equilibrium. Authors distinguish here two types of processes according to their intensity [66-71]: the normal and the hyperstabilization. In the first case, $\Delta \mathrm{A}_{\mathrm{F}}$ values approximately equal to $65 \mathrm{~K}$ are reached, while in the second, $\Delta \mathrm{A}_{\mathrm{F}}$ values close to $250 \mathrm{~K}$ have been observed [67]. In this case, the annealing out of the excess vacancies, while martensite stabilization was taking place, deserved further attention, since, as mentioned before, changes in vacancy concentrations were also associated with $\mathrm{M}_{\mathrm{S}}$ variations due to its effect on $\mathrm{Be}$ concentration [59]. This characteristic is of particular interest in separating the contributions of the different phenomena. This was taken into consideration in the design 
of stabilization tests which were performed after getting precise reference states with vacancy concentrations close or equal to equilibrium [72]. In this way, the effect of the annealing out of vacancies could be disregarded, the reference state being exactly recovered by aging the austenitic phase after the tests used to measure the martensite stabilization. Sade et al. [72] obtained reference states by quenching $\mathrm{Cu}-\mathrm{Al}-\mathrm{Be}$ single crystals from $1123 \mathrm{~K}$ down to water at $373 \mathrm{~K}$, keeping the specimens for $60 \mathrm{~min}$ at this temperature, and cooling down in air to room temperature. Stabilization tests following the same procedure described in [62] were performed at temperatures in the range from $333 \mathrm{~K}$ up to $393 \mathrm{~K}$. The largest stabilization effects were obtained at $393 \mathrm{~K}$ where $\Delta \mathrm{A}_{\mathrm{F}}$ reached $7 \mathrm{~K}$ after aging in martensite for 2 days. Smaller $\Delta \mathrm{A}_{\mathrm{F}}$ values were obtained for lower aging temperatures. It should be noted here that saturation had not been reached after the mentioned aging time interval. The measured stabilization effect is clearly a diffusive effect and completely reversible. This could be verified in all cases by checking that the stress-strain curve characterizing the reference state is completely recovered, within the resolution of the experiments. These results allow concluding that the stabilization of martensite in $\mathrm{Cu}-$ $\mathrm{Al}-\mathrm{Be}$ can take place with the equilibrium concentration of vacancies. The occurrence of dynamic stabilization has been also verified by performing pseudoelastic cycling experiments [73, 74].

A mean field model described in [75] was used to calculate the free energy variations that are produced in the austenite and in the martensite by considering specific atom interchanges and evaluating the enthalpy and entropy corresponding to arbitrary atom configurations. The basic ideas behind these calculations draw inspiration from the study on $\mathrm{Cu}-\mathrm{Zn}-\mathrm{Al}$ by Abu Arab and Ahlers [62], where a very good agreement between results and modeling was reported. In that case, the assessment of free energy changes were obtained by means of the occupation probabilities of each element in the considered sublattices. A strong support to their atom interchange model was provided by the results reported by Nakata et al. [76]. These authors, using atomic site location by channeling-enhanced microanalysis (usually known as ALCHEMI), experimentally determined that during stabilization of martensite, an interchange between $\mathrm{Cu}$ and $\mathrm{Zn}$ atoms and a decrease in the density of stacking faults take place. They further reported a correlation between the amount of pair interchanges and the shift of transformation temperatures during stabilization, while no correlation between the amount of stabilization and the density of stacking faults has been observed. In this sense, these authors provide an additional validation to the model which explains stabilization of martensite in $\mathrm{Cu}-\mathrm{Zn}-\mathrm{Al}$ alloys by pair interchanges of $\mathrm{Cu}$ and $\mathrm{Zn}$ atoms.
Reverting to the present calculations, the elements present in the alloy, their compositions, the types of order preferred by the austenite and the pair interchange energies are the input variables for the model. The stability of each phase was then tested as a function of atom interchanges between neighboring positions within a reasonable distance. More details can be found in [72, 75]. A comparison of results for a $\mathrm{Cu}-\mathrm{Zn}-\mathrm{Al}$ and a $\mathrm{Cu}-\mathrm{Al}-\mathrm{Be}$ prototypical alloy at room temperature will be presented next.

In Table 1, the austenitic pair interchange energies associated to the nearest and the next-nearest-neighbor pairs (denoted by the superscript in parenthesis) taken from [42] are presented, together with alloy compositions. To avoid using the Boltzmann constant $k_{B}$ in the calculation of the entropy, all the energies were divided by $k_{B}$, and therefore the unit for energy is the Kelvin. Departing from the $\mathrm{L} 2{ }_{1}$ order described by Eq. (4), the ground state atom population in the austenite at room temperature can be calculated. The minimum free energy is obtained with an atom distribution best described by the sublattice configurations included at the bottom of Table 1, where the particular atomic compositions of each sublattice are also indicated. This atom configuration is consistent with a little degree of short-range disorder. Note that for both alloys, the $\mathrm{Cu}$ atom concentration on sublattice 4 reaches 0.02 at. $\%$ in this initial state.

Table 2 shows the pair interchange energies for the martensite. They were obtained as described in [72]. With these sets of values, the main stabilization mechanism could be associated with the first neighbor interchange between $\mathrm{Cu}$ atoms in sublattices 1 and 2 with either $\mathrm{Zn}$ atoms from sublattice $3(\mathrm{Cu}-\mathrm{Zn}-\mathrm{Al})$ or $\mathrm{Be}$ atoms from sublattice $4(\mathrm{Cu}-\mathrm{Al}-\mathrm{Be})$. In Fig. 2, the free energy variation as a function of the amount of interchanges can be observed.

The variation of the free energy of the martensite in the $\mathrm{Cu}-\mathrm{Zn}-\mathrm{Al}$ alloys presents a minimum at around 175,000 interchanges. This represents the limit for martensite stabilization because further interchanges results in an increase of the martensite free energy. This value corresponds to an interchange of around $2 \%$ of the total number of atom pairs that can be defined in sublattice 3 . In the case of the $\mathrm{Cu}-\mathrm{Al}-\mathrm{Be}$ alloy, the limit for stabilization is reached only after emptying completely sublattice 4 of Be atoms. This means that for this latter system, the maximum magnitude of stabilization is a consequence of the exhaustion of the possible available interchanges and not due to the existence of a minimum in the martensite free energy curve. In both cases, the free energy of the austenite increases monotonically. The free energy variation for both phases at the maximum degree of stabilization is also presented in Table 2. For example, the reached values in $\mathrm{Cu}-\mathrm{Zn}-\mathrm{Al}$ are $390 \mathrm{~J} / \mathrm{mol}$ in the austenite and $-250 \mathrm{~J} / \mathrm{mol}$ 
Table 1 Austenite. Pair interchange energies in $\mathrm{Cu}-\mathrm{Zn}-\mathrm{Al}$ and $\mathrm{Cu}-$ $\mathrm{Al}-\mathrm{Be}$ obtained from [42] and composition of the considered alloys (input data). Ground state atomic composition for each sublattice (calculated)

\begin{tabular}{lll}
\hline Alloy & $\mathrm{Cu}-\mathrm{Zn}-\mathrm{Al}$ & $\mathrm{Cu}-\mathrm{Al}-\mathrm{Be}$ \\
\hline $\begin{array}{l}\text { Pair interchange energies in } \\
\text { the austenite }\end{array}$ & $W_{\mathrm{CuZn}}^{(1)}=850 \mathrm{~K}$ & $W_{\mathrm{CuAl}}^{(1)}=1210 \mathrm{~K}$ \\
& $W_{\mathrm{CuZn}}^{(2)}=485 \mathrm{~K}$ & $W_{\mathrm{CuAl}}^{(2)}=900 \mathrm{~K}$ \\
& $W_{\mathrm{CuAl}}^{(1)}=1150 \mathrm{~K}$ & $W_{\mathrm{CuBe}}^{(1)}=635 \mathrm{~K}$ \\
& $W_{\mathrm{CuAl}}^{(2)}=860 \mathrm{~K}$ & $W_{\mathrm{CuBe}}^{(2)}=125 \mathrm{~K}$ \\
& $W_{\mathrm{ZnAl}}^{(1)}=-100 \mathrm{~K}$ & $W_{\mathrm{AlBe}}^{(1)}=-85 \mathrm{~K}$ \\
& $W_{\mathrm{ZnAl}}^{(2)}=400 \mathrm{~K}$ & $W_{\mathrm{AlBe}}^{(2)}=330 \mathrm{~K}$ \\
\hline
\end{tabular}

Austenite ground state atomic distribution [at.\%]

Sublattice $1 \quad \mathrm{Cu}-0.10 \mathrm{Zn} \quad \mathrm{Cu}-0.02 \mathrm{Be}$

Sublattice $2 \quad \mathrm{Cu}-0.10 \mathrm{Zn} \quad \mathrm{Cu}-0.02 \mathrm{Be}$

Sublattice $3 \quad \mathrm{Cu}-28.79 \mathrm{Zn} \quad \mathrm{Cu}-3.10 \mathrm{Be}$

Sublattice $4 \quad \mathrm{Cu}-36.98 \mathrm{Zn}-63.00 \mathrm{Al} \quad \mathrm{Cu}-90.52 \mathrm{Al}-9.46 \mathrm{Be}$

in the martensite. Based on thermodynamic arguments [44], these free energy variations can be expressed in terms of equivalent increments of $A_{F}$. The respective values are given at the bottom of Table 2 .

It can be observed that for the martensite in $\mathrm{Cu}-\mathrm{Al}-\mathrm{Be}$, the models predict a nearly double stabilization value compared to $\mathrm{Cu}-\mathrm{Zn}-\mathrm{Al}$. Whether this condition might be reached depends on the kinetic barriers to the interchanges.

\section{Austenite Under Stress: The Atom Distribution will also Change}

A subtle evolution in the critical stress required to induce the martensitic transformation in tension has been detected when the austenite is aged under an applied stress $(\sigma)$ in the elastic range, i.e., below the critical stress to induce the martensite at the testing temperature. Such phenomenon was observed to occur both in $\mathrm{Cu}-\mathrm{Zn}-\mathrm{Al}$ [77] and in $\mathrm{Cu}-$ $\mathrm{Al}-\mathrm{Be}$ [72] SMA. It has been verified that the magnitude and kinetics of this evolution depends on temperature, on the aging time and on $\sigma$ [78]. The process is reversible in the sense that there is a unique critical transformation stress value associated with each $\sigma$ value applied during aging, provided enough time has been elapsed. In case of specimens with a vacancy concentration near equilibrium at the testing temperature, the measured stress variation is around $1 \mathrm{MPa}$, favoring the appearance of the martensite after the austenite was aged under load.

The previously used mean field model can be used to explore the interchanges that could be responsible for this
Table 2 Martensite. Pair interchange energies in $\mathrm{Cu}-\mathrm{Zn}-\mathrm{Al}$ and $\mathrm{Cu}-$ $\mathrm{Al}-\mathrm{Be}$ following the procedure reported in [72] and composition of the considered alloys (input data). Preferred atomic composition for each sublattice, free energy variation of each phase and maximum theoretical stabilization magnitude (calculated)

\begin{tabular}{lll}
\hline Alloy & $\mathrm{Cu}-\mathrm{Zn}-\mathrm{Al}$ & $\mathrm{Cu}-\mathrm{Al}-\mathrm{Be}$ \\
\hline $\begin{array}{l}\text { Pair interchange energies in } \\
\text { the martensite }\end{array}$ & $m_{\mathrm{CuZn}}^{(1)}=780 \mathrm{~K}$ & $m_{\mathrm{CuAl}}^{(1)}=1150 \mathrm{~K}$ \\
& $m_{\mathrm{CuZn}}^{(2)}=60 \mathrm{~K}$ & $m_{\mathrm{CuAl}}^{(2)}=215 \mathrm{~K}$ \\
& $m_{\mathrm{CuAl}}^{(1)}=1100 \mathrm{~K}$ & $m_{\mathrm{CuBe}}^{(1)}=540 \mathrm{~K}$ \\
& $m_{\mathrm{CuAl}}^{(2)}=195 \mathrm{~K}$ & $m_{\mathrm{CuBe}}^{(2)}=-110 \mathrm{~K}$ \\
& $m_{\mathrm{ZnAl}}^{(1)}=-10 \mathrm{~K}$ & $m_{\mathrm{AlBe}}^{(1)}=-10 \mathrm{~K}$ \\
& $m_{\mathrm{ZnAl}}^{(2)}=285 \mathrm{~K}$ & $m_{\mathrm{AlBe}}^{(2)}=235 \mathrm{~K}$ \\
\hline Composition [at.\%] & $\mathrm{Cu}-16.49 \mathrm{Zn}-$ & $\mathrm{Cu}-22.63 \mathrm{Al}-$ \\
& $15.75 \mathrm{Al}$ & $3.15 \mathrm{Be}$ \\
\hline
\end{tabular}

Martensite preferred atomic distribution [at.\%]

Sublattice $1 \quad \mathrm{Cu}-10.51 \mathrm{Zn} \quad \mathrm{Cu}-4.74 \mathrm{Be}$

Sublattice $2 \quad \mathrm{Cu}-10.51 \mathrm{Zn} \quad \mathrm{Cu}-4.75 \mathrm{Be}$

Sublattice $3 \quad \mathrm{Cu}-7.95 \mathrm{Zn} \quad \mathrm{Cu}-3.10 \mathrm{Be}$

Sublattice $4 \quad \mathrm{Cu}-36.98 \mathrm{Zn}-\quad \mathrm{Cu}-90.52 \mathrm{Al}-$

63.00Al 0.01Be

Free energy variation for stabilization

$\begin{array}{lll}\text { Austenite } & 390 \mathrm{~J} / \mathrm{mol} & 350 \mathrm{~J} / \mathrm{mol} \\ \text { Martensite } & -250 \mathrm{~J} / \mathrm{mol} & -830 \mathrm{~J} / \mathrm{mol} \\ \text { Maximum degree of } & 450 \mathrm{~K} & 820 \mathrm{~K}\end{array}$

stabilization $\Delta \mathrm{A}_{F}$

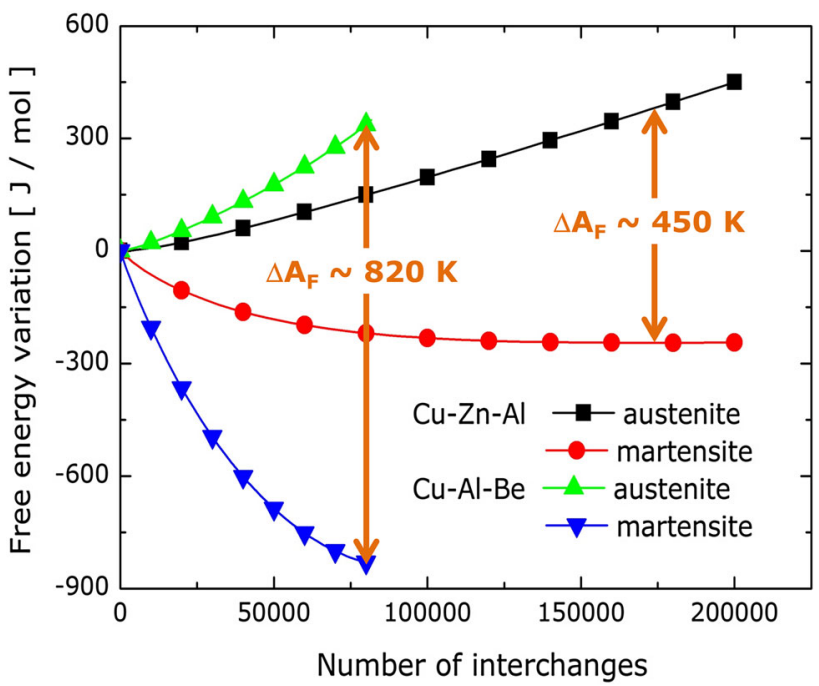

Fig. 2 Free energy variations of austenite and martensite as a function of the amount of nearest-neighbor interchanges for $\mathrm{Cu}-\mathrm{Zn}$ $\mathrm{Al}$ and $\mathrm{Cu}-\mathrm{Al}-\mathrm{Be}$ alloys. See text for details about the atom pairs interchanges. The maximum possible stabilization of the martensite expressed as a transformation temperature shift is indicated by the double arrow lines 
effect. The drawback of not having included an elasticity term in the formulation of the free energy has been surpassed by releasing the condition of decreasing austenite energy during aging. It was only requested that these values do not increase in excess, allowing for a stress assisted diffusion. Such a condition can be observed in Fig. 3 and Table 3, where the free energy of the austenite is shown to hardly deviate from the reference value, in less than $1 \mathrm{~J} / \mathrm{mol}$. Simultaneously, the martensite is favored by these atom interchanges as can be seen in Table 3 (negative values for the martensite in both systems). Proceeding in a similar way as mentioned before, the transformation stress shifts were calculated and shown at the bottom of Table 3 . They are in good agreement with the measured values.

The driving force for these interchanges has been explained by comparing the metallic atom radius of the elements. In the order of decreasing size, they are $143 \mathrm{pm}$, $134 \mathrm{pm}, 128 \mathrm{pm}$ and $112 \mathrm{pm}$ for $\mathrm{Al}, \mathrm{Zn}, \mathrm{Cu}$, and $\mathrm{Be}$, respectively. As the $\mathrm{Al}$ atoms are located on sublattice 4, it

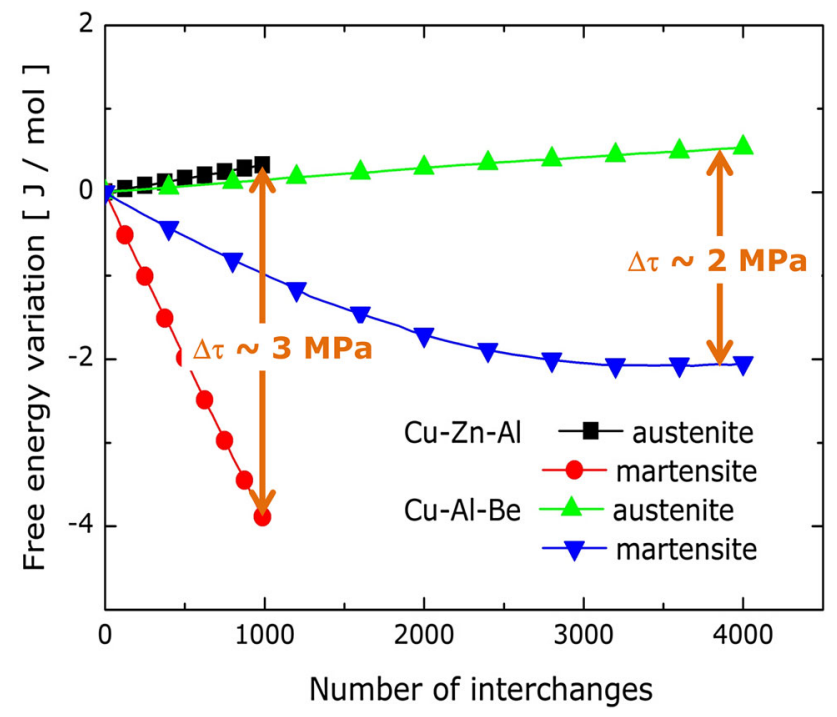

Fig. 3 Free energy variation of austenite and martensite as a function of the amount of nearest-neighbor interchanges for two prototypical alloys. See text for details about the interchanges. The maximum possible shifts in critical transformation stresses are indicated by the double arrow lines

Table 3 Principal outcomes of the model applied to the austenite aged under load is possible to find in $\mathrm{Cu}-\mathrm{Zn}-\mathrm{Al}$ a $\mathrm{Zn}$ atom on sublattice 3 surrounded by four next-nearest-neighbor $\mathrm{Al}$ atoms in a plane perpendicular to the Bain axis (the one privileged by the applied load). These four $\mathrm{Al}$ atoms will compress the $\mathrm{Zn}$ atom favoring his interchange with a smaller atom like $\mathrm{Cu}$, also belonging to sublattice 3 . The selected $\mathrm{Cu}$ atoms for the interchange were those leaving the most ample space, i.e., those surrounded by four $\mathrm{Zn}$ atoms in sublattice 4 in a neighboring parallel plane, up or down. A similar explanation has been found for $\mathrm{Cu}-\mathrm{Al}-\mathrm{Be}$, by interchanging in this case the compressed $\mathrm{Cu}$ atoms on sublattice 3 with the nearest $\mathrm{Be}$ from the same sublattice in neighboring planes. In the case of $\mathrm{Cu}-\mathrm{Zn}-\mathrm{Al}$, no further interchanges are possible, limiting the stress shift to $3 \mathrm{MPa}$. On the other hand in $\mathrm{Cu}-\mathrm{Al}-\mathrm{Be}$ more interchanges are available and the shift limit seems to appear due to the increase in the free energy of the austenite.

\section{Concluding Remarks}

The effect of changing atomic order configurations by diffusion of point defects on the relative stability between the austenitic and martensitic phases in $\mathrm{Cu}$-based shape memory alloys was reviewed. The main highlights that can be drawn from analysis are listed as follows:

- The atom configuration corresponding to the perfect order of the austenite phase is never reached. Although, even at room temperature, the configurational entropy warrants some degree of disorder, the main disordering contribution arises from the previous thermal and/or mechanical treatment, whatever it be.

- Changes in austenite-martensite relative phase stability reported so far in the literature can be explained both qualitatively and quantitatively through the evaluation of the free energy of the phases, after computing appropriate interchanges of atoms pairs in neighboring positions.

- The possible shifts of the critical transformation temperatures and stresses are limited either by the amount of the available pairs for the atom interchange or by vacancy kinetic reasons that might hinder

\begin{tabular}{lll}
\hline $\begin{array}{l}\text { Alloy } \\
\text { Composition [at.\%] }\end{array}$ & $\begin{array}{l}\mathrm{Cu}-\mathrm{Zn}-\mathrm{Al} \\
\mathrm{Cu}-16.49 \mathrm{Zn}-15.75 \mathrm{Al}\end{array}$ & $\begin{array}{l}\mathrm{Cu}-\mathrm{Al}-\mathrm{Be} \\
\mathrm{Cu}-22.63 \mathrm{Al}-3.15 \mathrm{Be}\end{array}$ \\
\hline $\begin{array}{l}\text { Free energy variation under load } \\
\text { Austenite }\end{array}$ & $0.3 \mathrm{~J} / \mathrm{mol}$ & $0.5 \mathrm{~J} / \mathrm{mol}$ \\
Martensite & $-3.9 \mathrm{~J} / \mathrm{mol}$ & $-2.1 \mathrm{~J} / \mathrm{mol}$ \\
Maximum degree of stability loss $\Delta \tau$ & $3 \mathrm{MPa}$ & $2 \mathrm{MPa}$ \\
\hline
\end{tabular}

Free energy variation for austenite and martensite in both alloys and estimated shift of transformation stresses (calculated) 
possible interchanges. The kind of limit depends on the specific phenomenon under study (e.g., martensite stabilization, reordering of the $\beta$-phase, etc.) and on the specific alloy family $(\mathrm{Cu}-\mathrm{Zn}-\mathrm{Al}, \mathrm{Cu}-\mathrm{Al}-\mathrm{Be}$, etc.).

Acknowledgements This study was supported by the ANPCyT, CONICET, CNEA, and the Universidad Nacional de Cuyo, Argentina.

\section{References}

1. Dejonghe W, Delaey L, De Batist R, Van Humbeeck J (1977) Temperature- and amplitude-dependence of internal friction in Cu-Zn-Al alloys. Metal Science 11(11):523-530

2. Koczak MJ, Herman H, Damask AC (1971) The production and annealing of point defects in $\beta$-CuZn. Acta Metall 19(4):303-310

3. Van Humbeeck J, Delaey L, Deruyttere A (1978) Pseudoelasticity in $\beta-\mathrm{Cu}-\mathrm{Zn}-\mathrm{Al}$ alloys. Zeitschrift für Metallkunde 69 (9):575-580

4. Janssen J, Van Humbeeck J, Chandrasekaran M, Mwamba N, Delaey L (1982) Stabilisation of martensite in copper-zinc-aluminium alloys. J Phys 43(12):C4-C720

5. Van Humbeeck J, Delaey L (1982) Evolution of the damping characteristics of $\mathrm{Cu}-\mathrm{Zn}-\mathrm{Al}$ martensitic alloys with time and temperature-the peaking effect. J Phys 43(12):691-695

6. Rapacioli R, Ahlers M (1979) The influence of short-range disorder on the martensitic transformation in $\mathrm{Cu}-\mathrm{Zn}$ and $\mathrm{Cu}-\mathrm{Zn}-\mathrm{Al}$ alloys. Acta Metall 27(5):777-784

7. Delaey L, Van Humbeeck J, Chandrasekaran M, Janssen J, Andrade M, Mwamba N (1981) Cu-Zn-Al shape memory alloys. Met Forum 4(3): 164-175

8. Van Humbeeck J, Janssen J, Mwamba N, Delaey L (1984) The stabilisation of step-quenched copper-zinc-aluminum martensite. Part I: the reverse transformation temperatures. Scr Metall 18 (9):893-898

9. Delaey L, Suzuki T, Van Humbeeck J (1984) The stabilisation of step-quenched copper-zinc-aluminum martensite. Part II: crystal structure and reordering. Scr Metall 18(9):899-903

10. Van Humbeeck J, Segers D, Delaey L (1985) The stabilization of step-quenched copper-zinc-aluminium martensite. Part III: the annealing-out of vacancies measured by positron annihilation. Scr Metall 19(4):477-480

11. De Graef M, Van Humbeeck J, Andrade M, Delaey L (1985) The stabilization of step-quenched copper-zinc-aluminium martensite. Part IV: changes in the microstructure. Scr Metall 19(5):643-646

12. Lovey FC, Pelegrina JL (1989) Unpublished results

13. Scarsbrook G, Cook JM, Stobbs WM (1984) The stabilization of martensite in $\mathrm{Cu}-\mathrm{Zn}-\mathrm{Al}$ shape memory alloys. Metall Trans A 15 (11):1977-1986

14. Segers D, Van Humbeeck J, Delaey L, Dorikens M, DorikensVanpraet L (1985) Positron annihilation study of defects in the cyclically transformed martensite phase in a $\mathrm{Cu}-\mathrm{Zn}-\mathrm{Al}$ alloy. Appl Phys Solid Surf 36(4):179-182

15. Segers D, Van Humbeeck J, Dorikens-Vanpraet L, Lemahieu I, Dorikens M (1988) Determination of the migration energy of quenched-in defects in the martensite phase of a $\mathrm{CuZnAl}$ alloy. Scr Metall 22(4):521-523

16. Chandrasekaran M, Cooreman L, Van Humbeeck J, Delaey L (1989) Martensitic transformation in CuZnAl: Changes in transformation entropy due to post quench aging in the $\beta$ or martensitic condition. Scr Metall 23(2):237-239
17. Cooreman L, Van Humbeeck J, Delaey L (1990) Thermoelectric power measurements on stabilised $\mathrm{Cu}-\mathrm{Zn}-\mathrm{Al}$ martensite. Acta Metall Mater 38(12):2663-2666

18. Kustov S, Golyandin S, Sapozhnikov K, Cesari E, Van Humbeeck J, De Batist R (2002) Influence of martensite stabilization on the low-temperature non-linear anelasticity in $\mathrm{Cu}-\mathrm{Zn}-\mathrm{Al}$ shape memory alloys. Acta Mater 50(11):3023-3044

19. Kustov S, Pons J, Cesari E, Van Humbeeck J (2004) Pinninginduced stabilization of martensite. Part I: stabilization due to static pinning of interfaces. Acta Mater 52(10):3075-3081

20. Kustov S, Pons J, Cesari E, Van Humbeeck J (2004) Pinninginduced stabilization of martensite. Part II: kinetic stabilization in $\mathrm{Cu}-\mathrm{Zn}-\mathrm{Al}$ alloy due to pinning of moving interfaces. Acta Mater 52(10):3083-3096

21. Kustov S, Pons J, Cesari E, Van Humbeeck J (2004) Chemical and mechanical stabilization of martensite. Acta Mater 52 (15):4547-4559

22. Kustov S, Corró M, Pons J, Cesari E, Van Humbeeck J (2006) Thermodynamic reversibility and irreversibility of the reverse transformation in stabilized $\mathrm{Cu}-\mathrm{Zn}-\mathrm{Al}$ martensite. Mater Sci Eng A 438-440:768-772

23. Van Humbeeck J, Delaey L, Chandrasekaran M (1989) The influence of post quench aging in the beta-phase on the transformation characteristics and the physical and mechanical properties of martensite in a Cu-Al-Ni shape memory alloy. ISIJ Int 29(5):388-394

24. Hurtado I, Segers D, Van Humbeeck J, Dorikens-Vanpraet L, Dauwe C (1995) Evolution of the positron annihilation lifetime for aging in $\beta$-phase $\mathrm{Cu}-\mathrm{Al}-\mathrm{Ni}-(\mathrm{Ti})-(\mathrm{Mn})$ shape memory alloys. Scr Metall Mater 33(5):741-747

25. Kustov S, Golyandin S, Van Humbeeck J, De Batist R (1996) Low frequency amplitude-dependent relaxation in $\mathrm{Cu}-\mathrm{Al}-\mathrm{Ni}$ crystals. J Phys IV 6(8):C8-C321

26. Kustov SB, Golyandin SN, Hurtado I, Van Humbeeck J, De Batist R (1996) Internal friction in Cu-Al-Ni crystals in martensitic phase and during temperature-induced martensitic transformation. J Phys IV 6(8):C8-C389

27. Chen Q-F, Zhao L-C, Stalmans R, Van Humbeeck J (2000) Effect of pre-aging on the transformation temperatures of $\mathrm{Cu}-\mathrm{Al}-\mathrm{Ni}$ single crystals. Cailiao Kexue yu Gongyi/Mater Sci Technol 8 (2):94-100

28. Chen QF, Zhao LC, Stalmans R, van Humbeeck J (2001) Influence of isothermal treatment on superelastic behavior of $\mathrm{Cu}$ 13.8Al-4.0Ni (mass fraction) single crystals. J Mater Sci Technol $17(1): 49-50$

29. Chen QF, Zhao LC, Stalmans R, van Humbeeck J (2001) Superelastic behavior and stabilization of stress-induced martensite in $\mathrm{Cu}-13.4 \mathrm{Al}-4.0 \mathrm{Ni}$ single crystals. Trans Nonferrous Metals Soc China 11(2):161-165

30. Benke M, Mertinger V, Nagy E, Van Humbeeck J (2007) Investigation of aging phenomena in $\mathrm{Cu}-\mathrm{Al}-\mathrm{Ni}$ based shape memory alloys. Mater Sci Forum 537-538:129-136

31. Cingolani E, Stalmans R, Van Humbeeck J, Ahlers M (1999) Influence of thermal treatments on the long range order and the two way shape memory effect induced by stabilization in $\mathrm{Cu}-\mathrm{Al}$ Be single crystals. Mater Sci Eng A 268(1-2):109-115

32. Kustov S, Golyandin S, Sapozhnikov K, Cesari E, Van Humbeeck J (2003) Mobility of quenched-in defects, non-linear anelasticity and stabilisation of martensite in copper-based alloys. J Phys IV 112:475-478

33. Kustov S, Pons J, Cesari E, Morin M, Van Humbeeck J (2004) Athermal stabilization of $\mathrm{Cu}-\mathrm{Al}-\mathrm{Be} \beta^{\prime}{ }_{1}$ martensite due to plastic deformation and heat treatment. Mater Sci Eng A 373(1-2):328 338

34. Kustov S, Pons J, Cesari E, Van Humbeeck J, Morin M (2004) Stabilization and hyperstabilization of $\mathrm{Cu}-\mathrm{Al}-\mathrm{Be} \beta^{\prime}{ }_{1}$ martensite 
by thermal treatment and plastic deformation. Mater Sci Eng A 378(1-2):283-288

35. Kustov S, Santamarta R, Cesari E, Sapozhnikov K, Nikolaev V, Fedorov V, Krymov V, Van Humbeeck J (2012) Mechanical spectroscopy of hyperstabilized martensites. Solid State Phenom $184: 355-360$

36. Kustov S, Santamarta R, Salas D, Cesari E, Sapozhnikov K, Van Humbeeck J (2012) Hyperstabilization of martensites. Funct Mater Lett 5(1):1250005

37. Kustov S, Golyandin S, Sapozhnikov K, Pons J, Cesari E, Van Humbeeck J (2006) Effect of off-stoichiometry on the mobility of point-like defects and damping in binary $\mathrm{Cu}-\mathrm{Al}$ martensites. Acta Mater 54(8):2075-2085

38. Cesari E, Kustov S, Golyandin S, Sapozhnikov K, Van Humbeeck $\mathrm{J}$ (2006) Mobility of point-like defects in $\mathrm{Cu}-\mathrm{Al}$ martensites. Mater Sci Eng A 438-440:369-373

39. Kustov S, Cesari E, Golyandin S, Sapozhnikov K, Van Humbeeck J, Gremaud G, De Batist R (2006) Low-temperature relaxation in faulted Cu-based martensites. Mater Sci Eng A 432 (1-2):34-39

40. Kustov S, Cesari E, Van Humbeeck J (2012) Effects of pinning and atomic ordering on damping properties and martensitic transformation of copper-based shape memory alloys. Solid State Phenom 184:366-371

41. Arneodo Larochette P, Condó AM, Ahlers M (2005) Stability and stabilization of $2 \mathrm{H}$ martensite in $\mathrm{Cu}-\mathrm{Zn}-\mathrm{Al}$ single crystals. Philos Mag 85(22):2491-2525

42. Pelegrina JL (2014) A simple model to predict long-range atomic ordering temperatures in Cu-based shape memory alloys. Philos Mag 94(24):2705-2723

43. López-Ferreño I, Breczewski T, López GA, Nó ML, San Juan J (2016) Stress-assisted atomic diffusion in metastable austenite $\mathrm{DO}_{3}$ phase of $\mathrm{Cu}-\mathrm{Al}-\mathrm{Be}$ shape memory alloys. Scr Mater 124:155-159

44. Ahlers M (1986) Martensite and equilibrium phases in $\mathrm{Cu}-\mathrm{Zn}$ and Cu-Zn-Al alloys. Prog Mater Sci 30(3):135-186

45. Pelegrina JL, Fabietti LM, Condó AM, Pozo López G, Urreta SE (2010) The influence of microstructure on the martensitic transformation in $\mathrm{Cu}-\mathrm{Zn}-\mathrm{Al}$ melt-spun ribbons. Philos Mag 90 (20):2793-2805

46. Planes A, Macqueron JL, Rapacioli R, Guénin G (1990) Martensitic transformation quenching effects in $\mathrm{Cu}-\mathrm{Zn}-\mathrm{Al}$ shapememory alloys. Philos Mag A 61(2):221-231

47. Planes A, Romero R, Ahlers M (1990) The martensitic transition temperature in ternary $\mathrm{Cu}-\mathrm{Zn}-\mathrm{Al}$ alloys. Influence of the L21 structure. Acta Metall Mater 38(5):757-763

48. Romero R, Salgueiro W, Somoza A (1992) Positron lifetime spectroscopy in quenched $\beta-\mathrm{Cu}-\mathrm{Zn}$-Al. Phys Status Solidi A 133 (2):277-282

49. Salgueiro W, Romero R, Somoza A, Ahlers M (1993) The postquench vacancy behavior in $\beta-\mathrm{Cu}-\mathrm{Zn}-\mathrm{Al}$. Phys Status Solidi A 138(1):111-118

50. Somoza A, Macchi C, Romero R (1997) Thermal generation of point defects in $\beta \mathrm{Cu}-\mathrm{Zn}-\mathrm{Al}$ alloys. Mater Sci Forum 255257:587-589

51. Sesma FG, Arneodo Larochette P, Pelegrina JL (2010) Influence of the experimental technique on the quench temperature dependence of the martensitic transformation temperature in $\mathrm{Cu}-$ $\mathrm{Zn}-\mathrm{Al}$ alloys. J Alloy Compd 502(2):356-359

52. de Castro Bubani F, Lovey FC, Sade M (2017) A short review on the interaction of precipitates and martensitic transitions in $\mathrm{Cu}-$ Zn-Al shape memory alloys. Funct Mater Lett 10(1):1740006

53. Tidu A, Eberhardt A, Bolle B, Moreau F, Heizmann JJ (2001) Orthorhombic lattice deformation of $\mathrm{CuAlBe}$ shape-memory single crystals under cyclic strain. J Appl Crystallogr 34(6):722729
54. Lopez-Ferreño I, Breczewski T, Ruiz-Larrea I, Lopez-Echarri A, Nó ML, San Juan J (2013) Thermal treatments and transformation behavior of $\mathrm{Cu}-\mathrm{Al}-\mathrm{Be}$ shape memory alloys. J Alloy Compd 577(Supplement 1):S463-S467

55. Sade M, Yawny A, Lovey FC, Torra V (2011) Pseudoelasticity of $\mathrm{Cu}-\mathrm{Al}-\mathrm{Be}$ single crystals: unexpected mechanical behavior. Mater Sci Eng A 528(27):7871-7877

56. Jurado M, Mañosa L, Planes A (1993) Influence of configurational atomic order on the relative stability of bcc and closepacked structures in Cu-based alloys. Phys Rev B 48(5):3540 3543

57. Planes A, Vives E, Castán T (1991) Diffusionless first-order phase transitions in systems with frozen configurational degrees of freedom. Phys Rev B 44(13):6715-6722

58. Romero R, Somoza A, Jurado MA, Planes A, Mañosa L (1997) Quenched-in defects and martensitic transformation in $\mathrm{Cu}-\mathrm{Al}-\mathrm{Be}$ shape memory alloys. Acta Mater 45(5):2101-2107

59. Mañosa L, Jurado MA, Gonzàlez-Comas A, Obradó E, Planes A, Zarestky J, Stassis C, Romero R, Somoza A, Morin M (1998) A comparative study of the post-quench behaviour of $\mathrm{Cu}-\mathrm{Al}-\mathrm{Be}$ and $\mathrm{Cu}-\mathrm{Zn}$-Al shape memory alloys. Acta Mater 46(3):1045-1053

60. Romero R, Somoza A, Mañosa Ll, Planes A (2003) Vacancies and the martensitic transition in Cu-based shape-memory alloys. A comparative study. In Journal de Physique IV France 112:471474

61. Planes A, Mañosa L, Jurado MA, Romero R, Somoza A (1997) Low temperature aging behaviour of quenched $\mathrm{Cu}-\mathrm{Al}-\mathrm{Be}$ shape memory alloy. In: Beyer J, Bottger A, Mulder JH (eds) Proceedings of the european symposium on martensitic transformations (ESOMAT97), Journal de Physique IV France 7, Colloque C5, Supplement au Journal de Physique III, Enschede, The Netherlands, 1-5 July 1997, C5, pp 305-310

62. Abu Arab A, Ahlers M (1988) The stabilization of martensite. Acta Metall 36(9):2627-2638

63. Arneodo Larochette P, Condó AM, Ahlers M (2005) Stability and stabilization of $2 \mathrm{H}$ martensite in $\mathrm{Cu}-\mathrm{Zn}-\mathrm{Al}$ single crystals. Philos Mag 85(22):2491-2525

64. Bidaux J-E (1991) Stabilization of 18R martensite and its effect on martensite to martensite transformation in $\mathrm{Cu}-\mathrm{Zn}-\mathrm{Al}$. Scr Metall Mater 25(8):1895-1899

65. Yawny A, Lovey FC, Sade M (2000) Pseudoelastic fatigue of $\mathrm{Cu}-\mathrm{Zn}-\mathrm{Al}$ single crystals: the effect of concomitant diffusional processes. Mater Sci Eng A 290(1-2):108-121

66. Kustov S, Pons J, Cesari E, Morin M (2002) Two-stage reverse transformation in hyperstabilized $\beta^{\prime}{ }_{1}$ martensite. Scr Mater 46 (11):817-822

67. Gonzalez CH, Guenin G, Morin M (2003) Effects of martensitic stabilization in $\mathrm{Cu}-\mathrm{Al}-\mathrm{Be}$ shape memory alloys. Proceedings of the ICOMAT'02, Helsinki, Finland, 10-14 June 3002, Journal de Physique IV 112 (1), pp 561-564

68. Kustov S, Pons J, Cesari E, Van Humbeeck J, Morin M (2004) Stabilization and hyperstabilization of $\mathrm{Cu}-\mathrm{Al}-\mathrm{Be} \beta_{1}^{\prime}$ martensite by thermal treatment and plastic deformation. Mater Sci Eng A 378(1-2):283-288

69. Gonzalez CH, de Araújo CJ, Quadros NF, Guénin G, Morin M (2004) Study of martensitic stabilisation under stress in $\mathrm{Cu}-\mathrm{Al}-$ Be shape memory alloy single crystal. Mater Sci Eng A 378(12):253-256

70. Dunne D, Morin M, Gonzalez C, Guenin G (2004) The effect of quenching treatment on the reversible martensitic transformation in CuAlBe alloys. Mater Sci Eng A 378(1-2):257-262

71. Dunne D, Ireland K, Gonzalez C, Morin M, Guénin G (2006) Hyperstabilisation of martensite in $\mathrm{Cu}-\mathrm{Al}-\mathrm{Be}$ alloys. Mater Sci Eng A 438-440(1):339-342 
72. Sade M, Pelegrina JL, Yawny A, Lovey FC (2015) Diffusive phenomena and pseudoelasticity in $\mathrm{Cu}-\mathrm{Al}-\mathrm{Be}$ single crystals. J Alloy Compd 622(1):309-317

73. Siredey N, Eberhardt A (2000) Fatigue behavior of $\mathrm{Cu}-\mathrm{Al}-\mathrm{Be}$ shape memory single crystals. Mater Sci Eng A 290(1-2):171179

74. Sade M, La Roca P, De Castro Bubani F, Lovey FC, Torra V, Yawny A (2015) Pseudoelastic cycling between austenite, 18R and $6 \mathrm{R}$ phases in $\mathrm{CuAlBe}$ single crystals. International conference on martensitic transformations (ICOMAT-2014). Materials today: proceedings V2 S3 S719 S722 (2015). https://doi.org/10. 1016/j.matpr.2015.07.383
75. Ahlers M, Pelegrina JL (2003) Aging of martensite: stabilisation and ferroelasticity in Cu-based shape memory alloys. Mater Sci Eng A 356(1-2):298-315

76. Nakata Y, Yamamoto O, Shimizu K (1993) Effect of aging in $\mathrm{Cu}$ Zn-Al shape memory alloys. Mater Trans JIM 34(5):429-437

77. Pelegrina JL, Ahlers M (2004) Influence of a constant stress during isothermal $\beta$-phase aging on the martensitic transformation in a $\mathrm{Cu}-\mathrm{Zn}-\mathrm{Al}$ shape memory alloy. Scr Mater 50(4):423427

78. Torra V, Pelegrina JL, Isalgue A, Lovey FC (2005) Metastable effects on martensitica transformation in SMA (I): recoverable effects by the action of thermodynamic forces in parent phase. J Therm Anal Calorim 81(1):131-135 